\title{
P I 6-50. Immune reconstitution and antiviral control of SIV following adoptive transfer of anti-CD3/28 expanded CD4+ T cells: Induction of antiviral control
}

\author{
N Onlamoon ${ }^{3}$, KA Rogers 3 , N Plagman³, A Lewis'3, A Mayne ${ }^{3}$, \\ K Pattanapanyasat ${ }^{1}$, L Basso ${ }^{2}$, P Orchard ${ }^{2}$, AA Ansari ${ }^{3}$ and F Villinger*3
}

Address: ${ }^{1}$ Mahidol Univeristy, Bangkok, Thailand, ${ }^{2}$ University of Minnesota, Minneapolis, MN, USA and ${ }^{3}$ Pathology, Emory University sh of Medicine \& Yerkes Nat Primate Research Center, Atlanta, GA, USA

* Corresponding author

from AIDS Vaccine 2009

Paris, France. 19-22 October 2009

Published: 22 October 2009

Retrovirology 2009, 6(Suppl 3):P279 doi:10.1 I86/I742-4690-6-S3-P279

This abstract is available from: http://www.retrovirology.com/content/6/S3/P279

(C) 2009 Onlamoon et al; licensee BioMed Central Ltd.

\section{Background}

HIV and SIV pathogenic infection is characterized by early CD4+ T cell dysfunction.

\section{Methods}

Using a protocol of optimized in vitro expansion of enriched CD4+ T cells, we have been able to induce longterm control of viremia in rhesus macaques chronically infected with SIVmac239.

\section{Results}

Antiviral control was characterized with the extended presence multifunctional antigen specific CD4 and CD8+ T cells detected even 1 year post transfer while viral loads remained mostly undetectable. Monitoring of trafficking and turnover of adoptively transferred anti-CD3/28 expanded CFSE labeled CD4+ T cells demonstrated extensive recirculation and dissemination of these cells with relatively slow homeostatic proliferation over time and long time engraftment in LTNP monkeys. In efforts to examine the long-term contribution of adoptively transferred anti-CD3/28 expanded CD4+ T cells, another set of monkeys was treated with transduced with a retroviral vector directing intracellular expression of the HSV-tk suicide gene and the extracellular expression of the nerve growth factor receptor (NGFR). Transduced cells enriched based on NGFR expression were expanded with anti-CD3/ 28 coated beads and transfused in SIV infected monkeys under short term ART. Two weeks following the last adoptive transfer, the transferred cells were selectively eliminated by ganciclovir administration, resulting in various levels of viral rebound after initial control. The data lends support to a long term therapeutic effect of adoptively transferred in vitro expanded CD4+ T cells even in the absence of transduction of antiviral moiety, these cells appear refractory to SIV production, for at least 2 weeks post expansion.

\section{Conclusion}

Thus, we demonstrate that partial replenishment of the CD4 (unsorted) compartment is sufficient to induce potent immune mediated control of viremia during SIV infection. 